\title{
A CIÊNCIA RESISTE
}

\author{
Science resists La ciencia resiste
}

\author{
Silvânia Siebert* \\ Andréia da Silva Daltoé ${ }^{* *}$ \\ Universidade do Sul de Santa Catarina, \\ Programa de Pós-Graduação em Ciências da Linguagem, Tubarão, SC, Brasil
}

O negacionismo na Ciência não é fenômeno recente. Galileu Galilei foi levado ao Tribunal da Inquisição em 1633 por defender e divulgar a teoria de Copérnico de que a Terra se movia ao redor do Sol: nega a Igreja Católica, por motivos óbvios; precisou negar seus estudos o físico e astrônomo italiano para não ir à fogueira. A História, todavia, mostraria depois que a teoria galileana, em palavras de Pêcheux (2006, p. 37-39), ao trazer a física como ciência social, iniciaria um movimento na construção do real físico como processo, marcando uma descontinuidade no continente da história.

Fazendo um voo no tempo, chegamos ao contexto da Pandemia, assim nominada pela Organização Mundial da Saúde em março de 2019: a Pandemia causada pela Covid19. Seu surgimento em escala global devastadora, conforme Birman (2020, p. 70), surpreendeu os diferentes Estados da cartografia internacional assim como a comunidade científica e médica, vendo-se todos, inicialmente, impotentes no confronto trágico e mortal com a Covid-19.

Em dois anos na luta contra o vírus, lançamos toda a expectativa em políticas de contenção e na criação de uma vacina, que, em tempo exíguo, foi possível graças à Ciência e a toda pesquisa já construída anteriormente no âmbito sanitário e de saúde pública. Com as vacinas foi possível, em poucos meses, que milhões de pessoas em dezenas de países tivessem recebido alguma dose contra a Covid-19.

Todavia, vimos que não bastavam vacinas disponíveis; dependíamos de políticas públicas que garantissem a imunização da população mundial, e não só. Vem sendo necessário lutar também contra o negacionismo que, como saída política de não enfrentamento à Covid, disseminou tratamentos precoces sem comprovação científica, além de levantar suspeita junto à população sobre a eficácia das vacinas autorizadas por órgãos competentes.

\footnotetext{
* Doutora em Linguística Aplicada pela Universidade Estadual de Campinas. Editora de Linguagem em (Dis)curso. ORCID: https://orcid.org/0000-0002-7852-0968. E-mail: silvania@cinemaistv.com.br.

** Doutora em Letras pela Universidade Federal do Rio Grande do Sul. Editora de Linguagem em (Dis)curso. ORCID: https://orcid.org/0000-0002-8370-6441. E-mail: andreia.daltoe@animaeducacao.com.br.
} 
Este cenário coloca-nos diante de contradições importantes e que aqui levantamos, não para serem resolvidas, mas justamente para pensar o papel do saber científico neste tempo. Mesmo a Ciência sendo um espaço legitimado e positivado em torno de um discurso de verdade, isso não a isola das implicações econômicas, políticas, históricas e ideológicas. Há a produção do conhecimento, mas há também a institucionalização e a gestão do conhecimento, podendo, conforme Orlandi (2017, p. 177), esta última se sobrepor à produção, "com todas as consequências que isso traz para o trabalho científico".

Sob os pressupostos de uma teoria materialista do discurso, tal como iniciada por Michel Pêcheux, entendemos o sentido sempre em disputa e, no percurso que aqui traçamos neste momento, defrontamo-nos com este litígio no processo de divulgação do conhecimento científico. Todo saber reunido sobre formas de contenção do vírus, necessidade de medidas de proteção, criação e disseminação da vacina vai precisar também enfrentar um outro inimigo - ora escancarado, ora invisível feito o vírus: um negacionismo que responde a interesses de uma política de morte e que atualiza, portanto, o pensamento de Foucault (1999, p. 51): "por trás de todo saber, de todo conhecimento, o que está em jogo é uma luta de poder. O poder político não está ausente do saber, ele é tramado com o saber".

Tal perspectiva nos leva a pensar que a dificuldade de enfrentamento à Pandemia não diz respeito apenas às condições de governabilidade e liderança dos governantes, mas a interesses difusos que fazem pensar que o imperativo da vida não é a maior preocupação.

Birman (2020, p. 56) também recupera Foucault quando afirma que, se medidas antecipatórias contra o vírus da Covid não foram tomadas para proteção da vida da população em vários países do mundo, “isso foi consequência direta de uma opção de ordem política feita por seus governantes, para não perturbar o bom andamento da economia neoliberal". E daí acrescentamos: uma economia que, além de pretender seguir seu curso independente do número de vítimas, cuidou de se aproveitar do próprio caos instaurado pela Pandemia para implementar políticas de interesse neoliberal.

Para Sousa Santos (2020), "a atual pandemia não é uma situação de crise claramente contraposta a uma situação de normalidade. Desde a década de 1980 - à medida que o neoliberalismo foi se impondo como a versão dominante do capitalismo e este foi se sujeitando mais e mais à lógica do setor financeiro -, o mundo tem vivido em permanente estado de crise". Para o autor, a pandemia veio clarear o modo como já vivemos uma política de exceção, que deixa morrer e à sorte alguns muitos em nome de interesses econômico-políticos. Ao mesmo tempo, tamanha claridade nos cega, no trabalho perspicaz da ideologia, que, daí trazendo Althusser (1985, p. 94), se marca por "impor (sem parecer fazê-lo, uma vez que se trata de 'evidências') as evidências como evidências, que não podemos deixar de reconhecer".

Esta problemática, que trazemos até aqui para falar das determinações que afetam o saber científico, não vêm, porém, para dizer de sua impotência. Pelo contrário. Acreditamos sempre em seu papel primordial na melhoria das condições de vida de uma formação social. Mas não podemos considerá-lo potente por si só para dar conta dos problemas que nos atingem. Os pesquisadores e cientistas brasileiros vivenciaram este enfrentamento não só nos cortes de verbas em pesquisa, por exemplo, como também na luta que precisaram travar contra o negacionismo na Ciência, que acabou fazendo parte 
da campanha do próprio Governo Federal. Por outro lado, isso os fez ganhar publicidade, já que temas como vacina e ciência tornaram-se pauta constante de debates políticos, jornalísticos, entre amigos e na família, levando-os a expandir as formas de divulgação do conhecimento científico.

A Pandemia obrigou pesquisadores e cientistas, portanto, a encontrar formas de divulgação do conhecimento para levar à população o que antes era bastante restrito aos espaços elitizados da academia, no interior dos muros das universidades e dos laboratórios. Hoje, cientistas como a bióloga Natalia Pasternak Taschner; Atila Iamarino, também biólogo e doutor em virologia; a pneumologista Margareth Maria Pretti Dalcolmo; e a médica infectologista Luana Araújo, entre outros tantos pesquisadores brasileiros importantes, passaram a ser figuras recorrentes em programas de televisão e nas redes sociais. Neste trabalho de divulgação, uma dupla função: divulgar suas pesquisas, mas também derrubar as tantas informações incorretas e, portanto, criminosas sobre a Covid-19.

Sobre o negacionismo, Henry Rousso (2008), historiador que pesquisa o tema na França, diz que é um movimento que nega os fatos históricos, nega as evidências do mundo, pautado em crenças pessoais. Para exemplificar como funciona o discurso dos negacionistas, usa o genocídio dos judeus na segunda guerra mundial, negado por acadêmicos e por grupos ligados à direita francesa, que, amparados em uma versão sem fundamentação em fatos históricos, alegam que os milhões de mortes não existiram. $\mathrm{O}$ pesquisador alerta para um falso revisionismo, uma vez que a proposição dos negacionistas não usa a Ciência para rever os fatos, mas sim versões de subjetividade pessoal. Se for conveniente dizer que não houve genocídio, o negacionista dirá.

É difícil compreender que o negacionismo, portanto, não significa simplesmente desconhecimento, ignorância perante dados, fatos, mas integra uma agenda na luta pelo poder, e, no caso da Pandemia em curso neste momento, podemos dizer que responde ao imperativo da morte: "uma opção de ordem política feita por seus governantes, para não perturbar o bom andamento da economia neoliberal" (BIRMAN, 2020, p. 56).

O que parece é que, embora saibamos que a Ciência não pode ser compreendida como um segmento à parte da sociedade de que faz parte, nunca ficou tão necessário contribuir para a reflexão sobre as articulações que estabelece com outros campos, como a economia, a política, a ética, a própria religião, etc. A Pandemia acabou desnudando algumas questões que talvez em um outro momento fossem passando despercebidas ou sentidas a longo prazo: o corte de gastos que as universidades públicas já vinham enfrentando apareceu comprometendo pesquisas urgentes para o enfrentamento à Covid19; o cancelamento de fomento à pesquisa; o corte de bolsas de estudo de mestrado e doutorado; a falta de medidas sanitárias básicas para a população; a carência de atendimento hospitalar em muitos lugares do País. Segundo pesquisadores e especialistas que acompanham os recursos investidos em Ciência, este ano houve um corte de trinta por cento: em torno de cinco bilhões de reais foram contingenciados ${ }^{1}$. Enfim, estes dados e as condições apontadas acima acabam confirmando o papel que a Ciência desempenha numa sociedade, ao mesmo tempo que implica aí a responsabilidade do poder público para garantir que os saberes científicos realmente ajudem a melhorar a qualidade de vida da população.

\footnotetext{
${ }^{1}$ Mais informações sobre o tema podem ser encontradas no link: https://bit.ly/2UXoSPG.
} 
Foucault (2021) estudou a relação entre o saber e o poder. Chegou à conclusão de que todo saber é político. Nesta analogia, vemos que a política hoje no Brasil valoriza pouco o saber científico e potencializa a disseminação de tratamentos alternativos e sem eficácia comprovada pela comunidade acadêmica. O negacionismo tornou-se discurso de poder e decidiu, em muito, o seguimento das ações de enfrentamento (ou de não enfrentamento) em muitos países. Conforme Birman (2020, p. 46), Trump, em sua campanha para o pleito de novembro de 2020, não quis arriscar desacelerar o setor econômico com os preparativos de combate à pandemia. Resultado: os Estados Unidos disparam com o maior número de doentes e mortos em todo o mundo. Lembrando que Birman (2020, p. 47) encerra esta obra ainda quando os EUA passavam pela primeira onda, e mesmo assim já surpreendia o autor o fato de que a economia mais rica do mundo e com diversos centros avançados de pesquisa médica liderava o ranking de morte. Segundo o autor, no Brasil, não foi diferente, já que, embora a Pandemia crescesse em número de mortes dia a dia, vimos o Presidente fustigar tanto “o Poder Judiciário, através do Supremo Tribunal Federal, quanto o Congresso Nacional, com a promoção de manifestações públicas de intenções claramente antidemocráticas, buscando apoio das Forças Armadas para estabelecer um regime autoritário e ditatorial" (2020, p. 61). Tudo isso, além de toda a campanha pró-kit-covid, resultado direto do negacionismo na Ciência, o Presidente rodou o País em motociatas, promovendo aglomeração, desestimulando o uso de máscaras e, como se não bastasse, levantando, o tempo todo, suspeitas em relação às vacinas.

É diante deste contexto tão complexo que reafirmamos o papel das Ciências Humanas na leitura de toda a conjuntura, fazendo ver o modo como os saberes constituídos, e mesmo os construídos em tão pouco tempo, podem dar conta de compreender o caminho do vírus no corpo humano, sua disseminação e contenção pela vacina, mas tudo isso encontra obstáculos se não se fizer intervir uma reflexão sobre o papel da política nas formas de governabilidade da Pandemia. Birman (2020, p. 68) reforça, desse modo, o papel de um discurso crítico da ciência, no qual se reconheça "as articulações fundamentais existentes entre o discurso científico com os discursos da política e da ética, no tecido íntimo de sua construção e produção de conceitos".

De nossa parte, reivindicamos ainda mais o papel fundamental que os estudos sobre o discurso do ponto de vista materialista desempenham, permitindo-nos problematizar, neste momento da Pandemia, os sentidos dados como fatalistas: "todos vão morrer um dia", "não há nada que se possa fazer", "não sou coveiro, e daí? etc. A Análise de Discurso (AD) nos provoca a desnaturalizar os sentidos dados, usando palavras de Pêcheux (2006, p. 32), como cobertura do real em sua homogeneidade lógica, que vai encontrar o sujeito pragmático em sua vontade de um "mundo semanticamente normal" (2006, p. 34). Não é pouca, portanto, a contribuição da $\mathrm{AD}$ quando questiona as determinações que afetam todo dizer; desse modo, expõe todo discurso em suas contradições, em sua natureza heterogênea, em sua dependência ao sujeito falante e à memória e à história que o afetam.

Pelo trabalho com o sentido, colocando-o em dependência das forças produtivas e relações de produção que determinam as sociedades humanas com a luta de classe que lhe corresponde, Pêcheux (1988, p. 73) nos leva a questionar os espaços discursivos logicamente estabilizados usados pelo poder, funcionando como "técnicas de gestão social dos indivíduos” (2006, p. 30) por Estados e Instituições. São técnicas que tentam 
nos governar ao modo de uma ciência exata: “"ninguém pode ignorar a lei' - porque esse real é impiedoso", (2006, p. 35), negando a todos o poder de questionar, de interpretar e, trazendo para o contexto da Pandemia, de pensar que há outras possibilidades de saída para a população que não seja ter de escolher entre a economia e a morte.

Desse modo, Pêcheux (1988) mostrará que uma ciência da língua não está desligada das relações políticas e de poder que regem uma formação social: na base econômica, a partir das condições materiais da produção capitalista, vemos a língua servindo:

\begin{abstract}
a necessidades da organização do trabalho, da mecanização e da estandardização que impõem uma comunicação sem equívocos - clareza 'lógica' das instruções diretivas [...] divisão social-técnica do trabalho, uma não-comunicação que separa os trabalhadores da organização da produção e os submete à 'retórica' do comando. (PÊCHEUX, 1988, p. 26).
\end{abstract}

A língua, portanto, vai servir às formas de comando da produção capitalista; consequentemente, também servirá para a forma jurídica deste sistema - aparelho ideológico de Estado principal da burguesia capitalista, usando palavras de Althusser (1985), que Pêcheux vai convocar para mostrar como o Direito também precisará de uma língua unívoca, capaz de "tirar os equívocos nos contratos, trocas comerciais, etc. [...] e, simultaneamente, manter o equívoco fundamental do 'contrato de trabalho', o que se pode resumir dizendo que, no direito burguês, 'todos os homens são iguais, mas há alguns que o são mais que outros"” (1988, p. 27).

Ao referir esta relação entre língua e as formas de comando numa sociedade como a nossa, encontramos novamente Foucault (1999, p. 50-51), ao desfazer o mito platônico da antinomia saber/poder, para pensar a relação que há entre o saber da ciência e o poder político. Para o autor, uma série de fenômenos não pode ser explicada a não ser que os relacionemos "a relações políticas que investem toda a trama de nossa existência" (1999, p. 31). Isso nos leva a ressaltar a importância dos estudos discursivos que nos ajudam a problematizar, questionar e mesmo resistir, segundo Gadet e Pêcheux (2004, p. 115), à "gestão discursiva do Estado capitalista moderno [...] administrando os bens e as dores, a vida e a morte".

$\mathrm{Na}$ administração do viver no planeta Terra buscamos encontrar uma cura para a doença provocada pelo vírus da Sars-CoV-2. Vacinas testadas por diferentes laboratórios mostram-se alternativas promissoras. Associadas a práticas de higiene e isolamento social, contribuem, sobremaneira, no controle da doença. No decorrer do percurso de tempo, o saber científico começou a tomar corpo em conversas do cotidiano. É cada vez mais considerado pelos brasileiros como fonte de conhecimento. Um exemplo vemos na vontade da população de ser vacinada. De acordo com a pesquisa de opinião feita pelo Instituto DataFolha, noventa e quatro por cento dos brasileiros querem ser vacinados ${ }^{2}$. Segundo Charaudeau (2016, p. 34), "os saberes do conhecimento tendem a estabelecer uma verdade sobre os fenômenos do mundo, mas uma verdade que existe fora da subjetividade do sujeito". A verdade está no mundo, no caso citado das vacinas, está na eficácia da proteção e na redução do número de mortes e de casos graves provocados pela doença.

\footnotetext{
2 Pesquisa publicada no site da CCN Brasil: https://www.cnnbrasil.com.br/saude/2021/07/13/datafolha-94dos-brasileiros-se-vacinaram-ou-pretendem-se-vacinar-contra-covid.
} 
A ciência dá resposta ao mundo das opiniões, porque "uma opinião não deve, pois, ser confundida com um saber sobre o mundo" (CHARAUDEAU, 2016, p. 33). Este é um fator bem importante do fazer científico: ele é testado, observado, analisado, refutado, aprovado, refeito. Mas, por uma comunidade, por um grupo, que trabalha em conjunto. Não é um saber individual, não é opinião, é conhecimento, é coletivo.

Neste ritual de produção e divulgação científica, as revistas especializadas desempenham papel fulcral. São elas que compartilham, entre os pares e a comunidade em geral, grande parte das pesquisas recém-realizadas. Daí o papel de periódicos como a Revista que aqui representamos: há 21 anos contribuindo para a reflexão crítica dos saberes constituídos e, em seu formato online, permitindo uma maior democratização das reflexões que propõe. Assume, portanto, nossa Revista o trabalho de divulgação científica, conforme proposto por Orlandi (2008, p. 149): “discursos da ciência fazendo seu percurso na sociedade e na história, publicizando-se e fazendo circular o saber de maneira particular". E tentando responder à pergunta que Orlandi traz nesta mesma discussão: "dado esse modo de circulação da ciência, que sentidos estão aí investidos?" (2008, p. 140), julgamos que seriam aqui todos aqueles que nos permitem desnaturalizar a ilusão de transparência entre mundo e linguagem, entre saberes e língua; deste modo, nos fazer refletir sobre as formas de dominação que impedem o questionamento, que nos fazem acreditar que saber e poder não andam de mãos dadas.

\section{REFERÊNCIAS}

ALTHUSSER, L. Aparelhos Ideológicos de Estado. Rio de Janeiro: Edições Graal, 1985.

BIRMAN, J. O trauma na pandemia do coronavírus. Rio de Janeiro: José Olympio, 2020.

CHARAUDEAU, P. A conquista da opinião pública: como o discurso manipula as escolhas políticas. Tradução de Angela M. S. Corrêa. São Paulo: Contexto, 2016.

CNN Brasil - Datafolha: 94\% dos brasileiros se vacinaram ou pretendem se vacinar contra Covid. Disponível em: https:/www.cnnbrasil.com.br/saude/2021/07/13/datafolha-94-dos-brasileiros-sevacinaram-ou-pretendem-se-vacinar-contra-covid

GADET, F.; PÊCHEUX, M. A língua inatingível: o discurso na história da linguística. Campinas: Pontes, 2004.

ROUSSO, H. Les racines du négationnisme en France. Cités, v. 36, n. 4, p. 51-62, 2008.

FOUCAULT, M. A verdade e as formas jurídicas. Rio de Janeiro: Nau Editora, 1999.

FOUCAULT, M. Microfísica do poder. Tradução de Roberto Machado. 11. ed. Rio de Janeiro/São Paulo: Paz \& Terra, 2021.

ORLANDI, E. P. Eu, tu, ele: discurso e real da história. Campinas: Pontes Editores, 2017.

ORLANDI, E. P. Discurso e texto: Formulação e circulação dos sentidos. Campinas, SP: Pontes Editores, 2008.

PÊCHEUX, M. Semântica e discurso: uma crítica à afirmação do óbvio. Campinas/SP: Editora da UNICAMP, 1988.

PÊCHEUX, M. O discurso: estrutura ou acontecimento. Campinas, SP: Pontes Editores, 2006.

SANTOS, B. de S. A cruel pedagogia do vírus. Coimbra: Almedina, 2020.

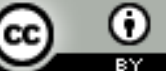

Este texto está licenciado com uma Licença Creative Commons Atribuição 4.0 Internacional. 